\title{
Urgent Off-Pump Revascularisation in ACS and Cardiogenic Shock with Anomalous Origin of Right Coronary Artery from Left Anterior Descending Artery: A Case Report
}

\author{
Surabhi Puri' ${ }^{1}$, Somya Puri², Deepak Puri ${ }^{3 *}$ \\ ${ }^{1}$ Department of Community Medicine, AIIMS, New Delhi, India \\ ${ }^{2}$ Maharishi Markandeshwar Medical College and Hospital, Solan, India \\ ${ }^{3}$ Department of CTVS, Max Superspeciality Hospital, Mohali, India \\ Email: *drdeepakpuri2@rediffmail.com
}

How to cite this paper: Puri, S., Puri, S. and Puri, D. (2021) Urgent Off-Pump Revascularisation in ACS and Cardiogenic Shock with Anomalous Origin of Right Coronary Artery from Left Anterior Descending Artery: A Case Report. World Journal of Cardiovascular Diseases, 11, 372-377. https://doi.org/10.4236/wjcd.2021.118036

Received: July 20, 2021

Accepted: August 23, 2021

Published: August 26, 2021

Copyright $\odot 2021$ by author(s) and Scientific Research Publishing Inc. This work is licensed under the Creative Commons Attribution International License (CC BY 4.0).

http://creativecommons.org/licenses/by/4.0/

\begin{abstract}
A 55-year-old female known case of essential hypertension and diabetes was brought to the Emergency Department in a drowsy state with cardiogenic shock. At presentation systolic BP was $70 \mathrm{~mm} \mathrm{Hg}$, pulse rate was $44 / \mathrm{min}$ and random blood sugar was $239 \mathrm{mg} / \mathrm{dl}$. Troponin I was 8.07. Electrocardiography showed junctional rhythm and bradycardia. Ejection Fraction (LVEF) was $15 \%$ - $20 \%$. Coronary angiography was done which revealed single vessel disease in LAD with anomalous origin of RCA from midsegment of LAD. Patient was immediately taken up for Off-pump Coronary Artery Bypass Grafting (OPCAB). Right saphenous vein graft was harvested and anastomosed proximally to aorta and distally to LAD on beating heart using Medtronic Octopus heart stabilizer and coronary shunts. Wound closed in layers after achieving complete hemostasis. Patient was taken off ventilatory support on first post-operative day and discharged in a stable condition on fourth post-operative day. Post-operative Echocardiography showed LVEF increased from $15 \%-20 \%$ at time of admission to $38 \%$ and $52 \%$ after 3 months and 12 months of surgery respectively.
\end{abstract}

\section{Keywords}

Right Coronary Artery, Anomalous Origin, Left Coronary Artery

\section{Introduction}

Coronary artery anomalies are very rare with an incidence varying between 0.2 - 
1.3 percent [1]. These are usually detected incidentally on coronary angiography. Origin of right coronary artery (RCA) from left anterior descending coronary artery (LAD) is one such anomaly which at times can lead to myocardial ischaemia even in the absence of atherosclerosis [2]. Incidence of anomalous RCA originating from LAD ranges from $0.024 \%$ to $0.066 \%$ and is often detected on coronary angiography [2]. Mostly RCA arises from proximal or mid segment of LAD but rarely it may also arise from distal LAD [3]. Anomalous RCA may course either anterior to pulmonary artery or in between the great vessels or rarely posterior to aorta [2]. Most commonly anomalous RCA courses between the great vessels causing external compression and ischemic symptoms, patients usually present with chest pain, dyspnea, palpitations, ventricular fibrillation, myocardial infarction, syncope or even sudden death [2] [4]. A few patients presenting with myocardial ischemia require either percutaneous or surgical revascularization [4] [5] [6] [7].

We present a case of a 55-year-old female who presented in a state of cardiogenic shock and on angiography was found to have single vessel disease in LAD with anomalous origin of RCA from midsegment of LAD. She was taken up for immediate off-pump revascularization instead of PTCA, because compression of anomalous RCA between great vessels could not be ruled out on preoperative coronary angiogram (Table 1).

Table 1. Demographic and clinical characteristics of the patient.

\begin{tabular}{|c|c|c|}
\hline S. No. & Parameter & \\
\hline 1. & Age & 55 years \\
\hline 2. & Gender & Female \\
\hline \multirow[t]{6}{*}{3.} & Clinical Features & \\
\hline & $>$ Dyspnea & Grade IV \\
\hline & $>$ Cardiogenic shock & + \\
\hline & $>$ Drowsiness & + \\
\hline & $>$ Pulse & 44/Min \\
\hline & $>\mathrm{BP}($ Systolic $)$ & $70 \mathrm{~mm} \mathrm{Hg}$ \\
\hline \multirow[t]{6}{*}{4.} & Blood Investigations & \\
\hline & $>$ Random Blood Sugar & $239 \mathrm{mg} / \mathrm{DL}$ \\
\hline & $>$ Trop I & 8.07 \\
\hline & $>$ Fasting Lipid Profile & $\uparrow L D L$ \\
\hline & & $\uparrow \mathrm{VLDL}$ \\
\hline & & $\uparrow$ Triglycerides \\
\hline \multirow[t]{2}{*}{5.} & Preoperative ECG & $>$ Bradycardia \\
\hline & & $>$ Junctional Rhythm \\
\hline \multirow[t]{5}{*}{6.} & Preoperative Echocardiography & Hypokinesia of: \\
\hline & & $>$ anterior wall \\
\hline & & $>$ apex \\
\hline & & $>$ apical septum \\
\hline & & $>$ Left Ventricular Ejection Fraction (LVEF): 15\%. \\
\hline \multirow[t]{2}{*}{7.} & Coronary Angiography & Critical single vessel disease in proximal LAD with \\
\hline & & anomalous origin of RCA from mid segment of LAD \\
\hline
\end{tabular}




\section{Case Report}

A 55 years old female known case of essential hypertension and diabetes presented with complaints of chest pain followed by sudden loss of consciousness associated with profuse sweating. She was brought to the Emergency Department in a drowsy state with cardiogenic shock. She had history of dyspnea (grade IV) for the last 2 days. At presentation systolic BP was $70 \mathrm{~mm} \mathrm{Hg}$, pulse rate was 44/min and random blood sugar was $239 \mathrm{mg} / \mathrm{dl}$. Initial Troponin I was 8.07. Fasting lipid profile revealed increased LDL, VLDL and triglycerides. Electrocardiography showed junctional rhythm and bradycardia. Echocardiography revealed Hypokinesia of anterior wall apex and apical septum and Left Ventricular Ejection Fraction (LVEF) of 15\%. Carotid Doppler was normal. Intra-aortic balloon pump was inserted immediately. Coronary angiography was done which revealed critical single vessel disease in proximal LAD with anomalous origin of RCA from midsegment of LAD (Figure 1(a) \& Figure 1(b)).

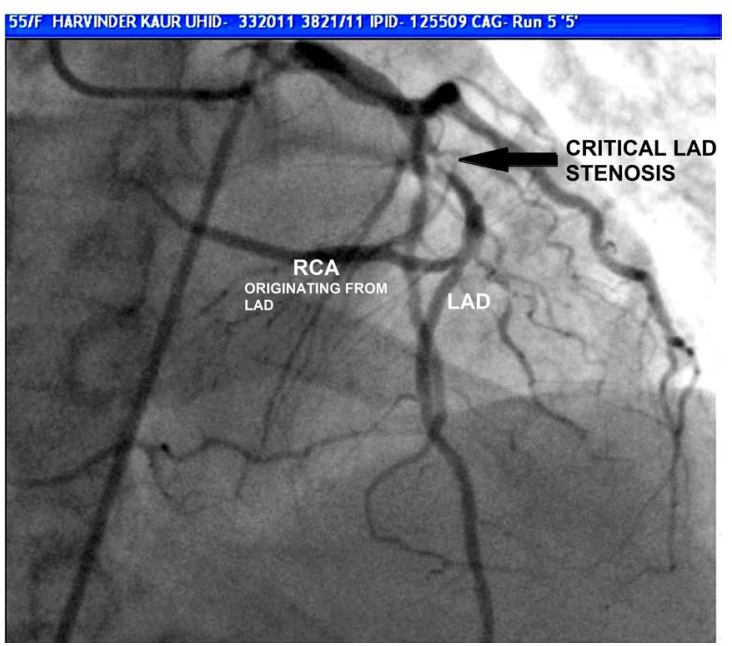

(a)

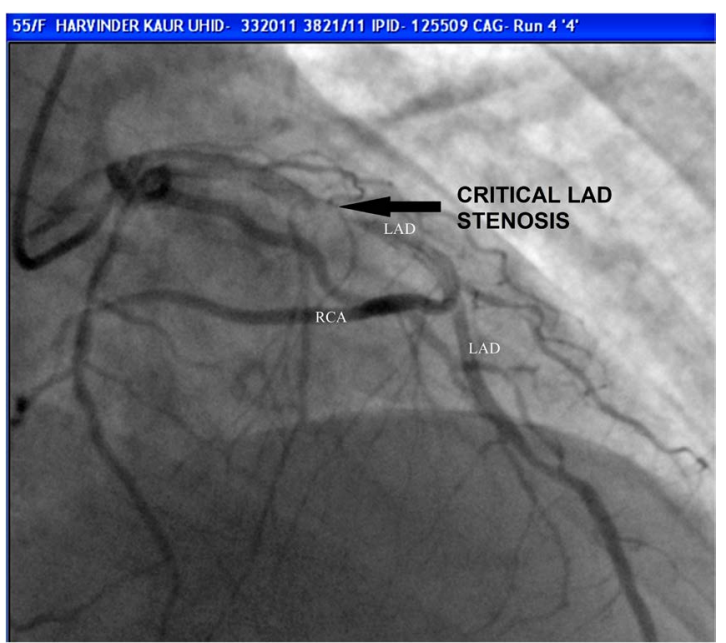

(b)

Figure 1. Coronary angiogram of patient showing anomalous origin of RCA from mid LAD and critical stenosis of proximal LAD. 


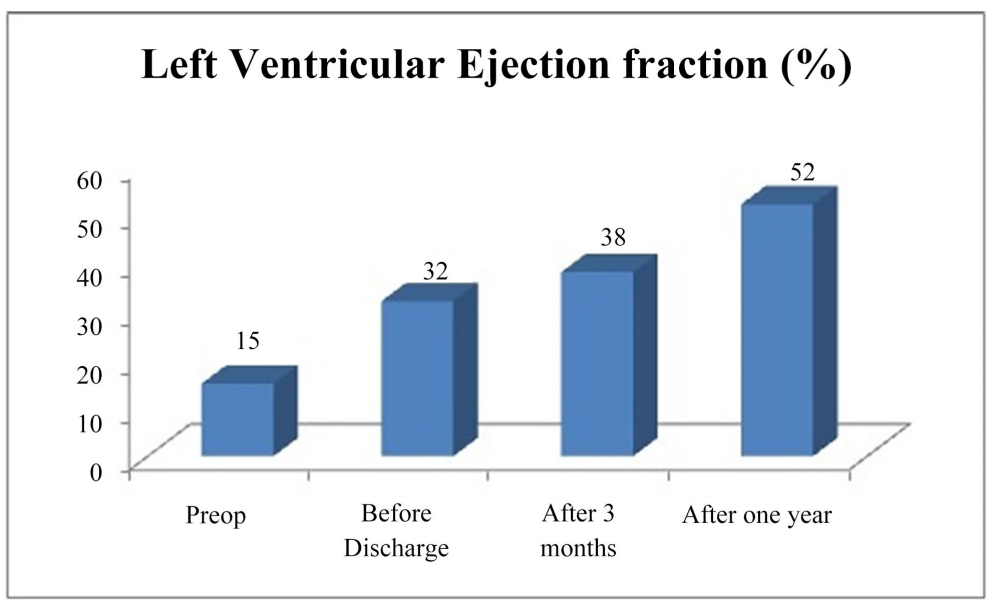

Figure 2. Improvement of left ventricular ejection fraction post OPCAB.

Patient was taken up for immediate Off-pump Coronary Artery Bypass Grafting (OPCAB) on high inotropic support and intra-aortic Balloon Pump (IABP). Troponin I at the time of surgery was 15.30. Median sternotomy with Pericardiotomy was done and massive pericardial and pleural effusion was seen and drained out. There was no extrinsic compression on the course of anomalous right coronary artery course. Right saphenous vein graft was harvested as patient needed immediate lifesaving revascularization and was not hemodynamically stable enough despite IABP along with high inotropes therefore was not suitable for left internal mammary artery harvesting and anastomosis. Proximal anastomosis was done on aorta and distally to LAD on beating heart using Medtronic Octopus heart stabilizer and coronary shunts. Hemostasis achieved. Atrial and ventricular pacing was put. Two mediastinal drains were inserted. Sternum was closed using steel wire in the figure of eight patterns and wound closed in layers. Post operatively she was taken off ventilatory support and IABP on first postoperative day and discharged in a stable condition on fourth postoperative day (Figure 2). Post op Echocardiography showed LVEF of 32\% before discharge and LVEF of $38 \%$ after 3 months and $52 \%$ at one year. Post operative recovery was uneventful. Patient was followed up in OPD for two years. Thereafter patient shifted abroad and is asymptomatic as informed telephonically for last 7 years.

\section{Discussion}

Coronary artery anomalies have previously been described in literature. RCA originating from left coronary system is a very rare variation of the single coronary artery anomaly that was first described in 1948 by White and Edwards [8] [9]. According to one study, it has been observed that $0.46 \%$ of the Indian population has anomalous RCA which is considered the highest among all population groups [10]. It is observed that anomalously arising and coursing coronary arteries are more prone to atherosclerosis causing myocardial ischemia [4]. Atherosclerosis has been reported in $11 \%$ of patients with congenital coronary artery 
anomalies [9]. But in a few patients ischemic symptoms develop even in the absence of atherosclerosis possibly due to factors like coronary vasospasm, acute angle take off, slit like orifice, intramural course of the vessel or external compression by the great vessels [2].

Prognosis usually depends on the course followed by the artery and the localization of the culprit atherosclerotic stenotic lesion [2]. Grave prognosis is seen when the anomalous artery crosses between pulmonary artery and aorta leading to myocardial ischaemia and sudden death from external compression especially during or immediately after exercise [2] [4]. Surgical revascularization was preferred to rule out such extrinsic compression. Prognosis is benign in all other situations. It is observed that RCA has been found to be the most commonly involved vessel (8). Many congenital anomalies such as Transposition of great vessels, Tetrology of Fallot, bicuspid aortic valve, ventricular septal defect are associated with single coronary artery (2). But in our case origin of the right coronary artery from LAD was without any other congenital malformation which is an even rarer finding (6).

Diagnosis of coronary artery anomalies is usually made by coronary angiography. Other non-invasive methods of diagnosis are coronary computed tomography angiography and cardiac magnetic resonance imaging (2).

Isolated case reports have been published in literature where patients had to undergo percutaneous (5) or surgical intervention $(4,6,7)$, however all of them had presented in a hemodynamically stable condition but in our case, the patient presented in the emergency department in a state of cardiogenic shock. The patient was relatively stabilized by elective IABP insertion and inotropic support. She was immediately shifted for OPCAB after coronary angiography. After anastomosing single right saphenous vein graft distal to LAD, good flow was obtained both in LAD as well as RCA and the patient stabilised. Advantage of immediate $\mathrm{OPCAB}$ in a patient with evolving myocardial ischemia and cardiogenic shock stabilized with IABP support was because less time elapsed between onset and revascularization by avoiding time consumed for cannulation and putting the patient on cardiopulmonary bypass and harvesting mammary artery. Benefits of this procedure are evident from the rapid decline of Troponin levels post operatively and remarkable improvement in left ventricular function assessed post operatively (preoperative LVEF was 15\%, before discharging the patient LVEF was $32 \%$ and at 3 months after surgery LVEF was $38 \%$ and at one year $52 \%)$.

\section{Conclusion}

Patients with single vessel disease can present with symptoms of coronary artery disease in a more critical condition in cases of dominant single coronary artery. Stenosis of LAD alone can lead to hemodynamic instability when RCA arises from LAD even though there is no significant disease in RCA. In such cases prompt off-pump revascularization of LAD with help of IABP support can sal- 
vage the myocardium and avoid catastrophic complications from occurring.

\section{Conflicts of Interest}

The authors declare no conflicts of interest regarding the publication of this paper.

\section{References}

[1] Hoffman, J.I., Kaplan, S. and Liberthson, R.R. (2004) Prevalence of Congenital Heart Disease. American Heart Journal, 147, 425-439.

https://doi.org/10.1016/j.ahj.2003.05.003

[2] Yurtdas, M. and Gulen, O. (2012) Anomalous Origin of the Right Coronary Artery from the Left Anterior Descending Artery: Review of the Literature. Cardiology Journal, 19, 122-129.

[3] Celik, M., Iyisoy, A. and Celik, T. (2011) Very Rare Anomalous Right Coronary Artery as a Terminal Extension of Left Circumflex Artery: A Case of Single Coronary Artery. Gülhane Tip Dergisi, 53, 130-132.

[4] Javangula, K. and Pankaj, K. (2007) Hyperdominant Left Anterior Descending Artery Continuing across Left Ventricular Apex as Posterior Descending Artery Coexistent with Aortic Stenosis. Journal of Cardiothoracic Surgery, 2, 42.

[5] Calabro, P., Bianca, R., Palmieri, R., Sordelli, C., Bigazzi, M.C. and Calabro, R. (2009) Evidence of Right Coronary from Mid-Left Anterior Descending Coronary: A Rare Case Coronary Anomalous Origin. European Heart Journal, 30, 565. https://doi.org/10.1093/eurheartj/ehn414

[6] Kamil, M., Vefali, V., Yilmazkaya, B., Goksel, S., Nisanglu, V., Yildiz, U., Yener, A. and Tasdemir, O. (2001) Right Coronary Artery Origin in Stenosed Left Anterior Descending Artery. Asian Cardiovascular and Thoracic Annals, 9, 128-129.

[7] Tokmakoglu, H., Bozoglan, O. and Ozdemir, L. (2010) Right Coronary Artery Originating from Left Anterior Descending Artery: A Case Report. Journal of Cardiothoracic Surgery, 5, 49.

[8] White, N.K. and Edwards, J.E. (1948) Anomalies of the Coronary Arteries. Report of Four Cases. Archives of Pathology, 45, 766-771.

[9] Tuncer, C., Batyraliev, T., Yilmas, R., Gokee, M., Eryonucu, B. and Koroglu, S. (2006) Origin and Distribution Anomalies of the Left Anterior Descending Artery in 70,850 Adult Patients: Multicenter Data Collection. Catheterization and Cardiovascular Interventions, 68, 574-585. https://doi.org/10.1002/ccd.20858

[10] Garg, N., Tewari, S., Kapoor, A., Gupta, D.K. and Sinha, N. (2000) Primary Congenital Anomalies of the Coronary Arteries: A Coronary Arteriographic Study. International Journal of Cardiology, 12, 39-46.

https://doi.org/10.1016/S0167-5273(00)00243-6 